https://doi.org/10.48009/2_iis_2019_73-82

Issues in Information Systems

Volume 20, Issue 2, pp. 73-82, 2019

\title{
HEALTHCARE PROFESSIONALS' PERCEPTION OF THE USABILITY OF ELECTRONIC MEDICAL RECORDS
}

\author{
Peter Draus, Robert Morris University, draus@rmu.edu \\ Sushma Mishra, Robert Morris University, mishra@rmu.edu \\ Kevin Slonka, University of Pittsburgh, kevinslonka@gmail.com \\ Natalya Bromall, Robert Morris University, bromall@rmu.edu \\ Kelli Slonka, Conemaugh Memorial Medical Center,kstanisl@conemaugh.org
}

\begin{abstract}
The goal of this study is to understand healthcare professionals' experience in using Electronic Medical Records (EMR) systems. Being the most active and frequent users of EMR, healthcare professionals have very important insights on whether the systems they use need to be improved and how to achieve a better experience using them. During the study, multiple EMR issues emerged that need to be addressed, such as policy compliance and system design. Many of these issues are especially important to address because they directly impact patient care. It was also found that demographic factors such as experience, age, or work environment of healthcare professionals have an influence on their perception of EMR.
\end{abstract}

Keywords: Electronic Medical Records (EMR), Electronic Health Records (EHR), healthcare information systems, survey, health care providers, workarounds

\section{INTRODUCTION}

Electronic Medical Record systems are adopted, in one form or another, by the majority of US hospitals. According to the National Coordinator of Health IT (2018), 97\% of all acute care hospitals and $86 \%$ of all office-based physicians demonstrated the use of certified health IT in 2017. The decision of adopting EMR and other healthcare IT systems are made primarily by the hospital administrators; however, registered nurses have the most potential to drive this adoption (Sackett et al., 2006) and are the most frequent users of such systems.

As the number one category of EMR users, nurses frequently report important issues with EMR that need to be addressed. One of the goals of this study is to address the issues that have a direct and immediate impact on patients and therefore are the top priority. For example, if a nurse cannot send an order or a prescription until it is verified by another healthcare professional, or when there is a delay in communication with another hospital system, this can delay timely patient care. When facing such obstacles, the nurses face the choice to not comply with the EMR protocols or to use workarounds. According to Dudding, Gephart, and Carrington (2018), nurses from multiple specialties report using workarounds due to constant interruptions, changes in communication patterns, and workflow. Such workarounds have good intentions behind; they are simply being a temporary solution to the increased workload and interruptions that delay patient care.

The second research question is related to the factors that affect the way healthcare professionals interact with EMR systems, such as demographic characteristics and the workplace environment. For example, the younger generation of professionals may have higher acceptance rates and a better understanding of EMR than the generation of professionals that had to change their habitual practices and adapt to technology development. Even with the regular training and increased proficiency with EMR use, other serious problems emerge, such as information misuse (Aluas, 2016) or unauthorized and late altering of the information (ED Legal Letter, 2018). The purpose of this study is determining which characteristics have any significant influence on the use of EMR. 
The goal of the study is answering the following research questions:

Research Question 1: What aspects of EMR systems impact patient care directly?

Research Question 2: What characteristics of healthcare professionals and their work environments impact issues with EMR systems?

\section{REVIEW OF LITERATURE}

The use of information technology in the medical field is a rather new concept. While machines have existed for some time, in the capacity of life supporting devices, the use of technology for informatics, the category under which Electronic Medical Records (EMR) fall, began in the late 1990s with the release of the American Academy of Colleges of Nursing's "The Essentials of College and University Education for Professional Nursing". This document highlighted the importance of informatics and the move from a mere resource to providing strategic value, specifically in the nursing field, despite the retreat of federal funding for implementation four years earlier (Sackett, Jones, \& Erdley, 2005).

The definition of the term EMR, however, is somewhat contested due to the existence of a similar term, Electronic Health Record (EHR). To be clear, an EMR system is considered a "digital version of the paper charts in the clinician's office" (Garrett \& Seidman, 2011, para 5). The EHR builds upon the EMR in that it allows healthcare providers to share patient data, thus allowing the record to contain data from all healthcare providers involved in the patient's care (even if those providers are not typical Primary Care Physicians, such as chiropractors, sports medicine clinicians, etc.) (Garrett \& Seidman, 2011).

Though the use of EMRs was exacerbated by the Health Insurance Portability and Accountability Act (Government Publishing Office, 2018; Adler-Milstein \& Jha, 2017), they offer many potential contributions to medicine. With health records being electronic and quickly accessible from anywhere, the ability for providers to measure disease level/distribution, report and investigate notifiable diseases, have access to complete, longitudinal patient records, and gain timely access to patient records are only a few of the possible benefits (Friedman, Parrish, \& Ross, 2013). All of these items point to the higher-level contributions: improved efficiency, patient care, and patient safety (Institute of Medicine, 2003).

\section{EMR Adoption and Champions}

This can be seen in the rapid adoption of EMR systems. DesRoches et al. (2013) found that in a four-year span from 2008 to 2012 the adoption of EMR systems at a minimal level rose from $9 \%$ to $44 \%$. Although these numbers seem promising, hospitals with at least a basic EMR system (27.3\%) are heavily outweighed by hospitals without any electronic system (56\%). The only category of hospitals where adoption outweighs opposition is major teaching hospitals (members of the Council of Teaching Hospitals), where basic adoption is $4.9 \%$ higher than no electronic system. The outlook, however, is not completely dire. More than $50 \%$ of hospitals use electronic means for essential public health functions, such as submitting data to immunization registries, submitting lab reports to public health agencies, and submitting syndromic data to public health agencies.

The adoption of EMR systems is most effectively driven by the healthcare professionals themselves. Nurses (Sackett, Erdley, \& Jones, 2006) and nursing leaders (Edwards, 2012) have the ability to drive adoption of EMR systems by impacting their "reception, design, development, and implementation" (p. 111). Nurses, however, aren't the only drivers of adoption. Primary care physicians (PCP) can also advance the cause for EMR systems due to their ability to increase efficiency and enhance productivity of PCP workloads (Bae \& Encinosa, 2016; Xierali et al., 2013). Additionally, other healthcare professionals in varying fields (e.g., dentistry, pharmacy, physiotherapy, allied health in long-term care facilities, etc.) can also drive EMR adoption should there be a need, though for some the need doesn't outweigh the various negative factors (Acharya, Schroeder, Schwei, \& Chyou, 2017; Fuji, Galt, Siracuse, \& Christoffersen, 2011; Wang \& Biedermann, 2012; Yung, 2017). 


\section{Acceptance Issues}

Though there are many groups within healthcare institutions that can drive adoption of an EMR system, there are always issues with the acceptance of any new technology. The most common issues are "limited or no access to computers, fear of change, nurses too busy to use computers, and nurses don't like computers" (Sackett, Erdley, \& Jones, 2006, p.251; Gesulga, Berjame, Moquiala, \& Galido, 2017). These reasons point to a key factor in adopting any electronic system: one's ability to use technology properly, which dovetails into EMR systems being user-friendly as a key acceptance factor (Aldosari, Al-Mansour, Aldosari, \& Alanazi, 2018; Sidek \& Martins, 2017; Gagnon et al., 2014). Syoubuzawa, Yamanouchi, \& Takeda (2006) asserted that education is "urgently required" (p. 819) to bring healthcare professionals' information knowledge and skills to an adequate level, with said education being most necessary for older workers (30 years old and above). This education must not only be in the area of EMR use but also misuse due to the ease of accessing/distributing medical information causing blurred ethical lines (Aluas, 2016). Given proper training on and implementation of EMR systems, most healthcare providers were more satisfied with electronic systems over traditional paper record systems (Choi, Chung, \& Lee, 2006).

\section{EMR Deficiencies and Workarounds}

While healthcare professional satisfaction is important, one of the higher-level contributions of an EMR system is patient safety. Single-vendor EMRs have led to a significant decrease in patient safety events in some studies (Bae, Rask, \& Becker, 2018), but the aforementioned issues with the implementation and use of an electronic system cannot be ignored. Patterson (2018) found that healthcare professionals would bypass what they perceived as "new additional steps in the workflow" (p. 281) and resort to using non-electronic methods (e.g., paper, whiteboards, etc.) to maintain situational awareness on some patients (Stevenson, Israelsson, Nilsson, Petersson, \& Bath, 2016). These methods, commonly referred to as workarounds, have traditionally been viewed as cause for concern about patient safety (Halbesleben, Wakefield, \& Wakefield, 2008; Meeks et al., 2014; Stutzer \& Rushton, 2015) even though, from the healthcare provider's perspective, workarounds are merely "work patterns [... created] to accomplish a crucial work goal within a system of dysfunctional work processes that prohibits the accomplishment of that goal or makes it difficult" (Morath \& Turnbull, 2005, p. 52). Barrett (2017) posits that this behavioral pattern affirms Adaptive Structuration Theory's principle that groups will evolve technology to better suit their needs. Workarounds, however, are not always negative and the ability to use them can lead to lower resistance and increased perception of EMR advantage and success (Barrett \& Stephens, 2017).

Continuing with reasons for implementing workarounds, other studies have cited work interruptions, heavier workloads, and altered communication patterns due to the implementation of an EMR (Dudding, Gephart, \& Carrington, 2018; Assis-Hassid, Grosz, Zimlichman, Rozenblum, \& Bates, 2019; Rathert, Porter, Mittler, \& FleidPalmer, 2019). Pagulayan, Eltair, \& Faber (2018) found that EMRs can lead to a drop in critical thinking skills due to the built-in automated processes/instructions, which inevitably leads to errors. Some healthcare professionals refuse to use the EMR at all, resorting to hiring medical scribes who follow the service providers and handle the secretarial work of entering data into the EMR. This is seen as bypassing instead of fixing the problem of a suboptimal EMR design (Schiff \& Zucker, 2016). It is believed by some healthcare professionals that EMR systems serve the purposes of hospital administrators more than those delivering care to the patients (Eason \& Waterson, 2013); however, this relates to expected vs. perceived user-friendliness of the EMR, which sometimes forces one to enter data in a way that is counterintuitive to how the healthcare professional prefers to interact with patients (Rathert, Porter, Mittler, \& FleidPalmer, 2019). Despite all of the seemingly contradicting studies, at the core lies a common theme: poor EMR design.

\section{METHODOLOGY}

An online survey was administered to a variety of healthcare workers. The questions consisted of Likert-type questions concerning their use of EMR and how the EMR impacts their ability to provide patient care. The scale consisted of "Almost Never", "Occasionally", "Often", "Regularly", and "Almost Daily" with the values going from 1-Almost Never to 5-Almost Daily. 139 subjects started the survey and 71 were complete, useable submissions.

Frequencies analysis and means tests were computed for Research Question 1 and ANOVA (including Tukey analysis and means testing) was completed for Research Question 2. A post hoc factor analysis was computed for relevant questions to enhance the results from Research Question 1. 


\section{RESULTS}

RQ1: What aspects of EMR systems impact patient care directly?

Seven of the 14 questions had the subjects selecting "often" or higher at over the $50 \%$ level. Means were calculated for all of these questions based on the values in the Likert scales. A factor analysis was run to determine the number of factors in this subset of seven questions. A two-factor solution was selected based on the Eigen Values. The two factors were labeled "EMR policy compliance issues" and "Systems design issues". Those questions, their mean values, and percentage for greater than or equal to "Often" and greater than or equal to "Regularly" are shown in Table 1 along with the factor loading for each question.

Table 1. Activities that health care providers feel impacts their patient care; "Often", "Regularly" or "Every Day."

\begin{tabular}{|l|l|l|l|l|}
\hline $\begin{array}{l}\text { Question } \\
\text { According to the hospital policies, electronic } \\
\text { medical record systems "require" second } \\
\text { healthcare professional to verify routine } \\
\text { procedures. }\end{array}$ & 2.79 & $54.79 \%$ & $32.88 \%$ & $\begin{array}{l}\text { EMR policy } \\
\text { compliance } \\
\text { issues }\end{array}$ \\
\hline $\begin{array}{l}\text { Multiple alerts/popups appear so often, that } \\
\text { they are simply closed and never fully read } \\
\text { (e.g. medication alerts) }\end{array}$ & 2.81 & $52.05 \%$ & $31.51 \%$ & $\begin{array}{l}\text { Systems design } \\
\text { issues }\end{array}$ \\
$\begin{array}{l}\text { The electronic medical records system is } \\
\text { designed more for hospital liability and less for } \\
\text { patient care. }\end{array}$ & 2.92 & $54.79 \%$ & $34.25 \%$ & \\
$\begin{array}{l}\text { Long waiting time for the pharmacies to verify } \\
\text { medications impacts the service provider's } \\
\text { ability to provide timely patient care. }\end{array}$ & $3.24^{*}$ & $75 \% *$ & $38.89 \%$ & \\
\hline $\begin{array}{l}\text { Multiple electronic medical record systems } \\
\text { have confusing and non-standard interfaces. }\end{array}$ & 2.82 & $54.79 \%$ & $26.03 \%$ & \\
\hline $\begin{array}{l}\text { Service providers need to provide medical care } \\
\text { to patients even if there are no actual recorded } \\
\text { orders in the electronic medical record system } \\
\text { (e.g. putting in verbal orders, providing } \\
\text { emergency care, etc.). }\end{array}$ & 3.12 & $65.75 \%$ & $39.73 \% *$ & \\
\hline $\begin{array}{l}\text { Being too dependent on electronic medical } \\
\text { records automation impacts the healthcare } \\
\text { provider's ability to think critically and be in } \\
\text { control. }\end{array}$ & 2.82 & $52.05 \%$ & $26.03 \%$ & \\
*indicates this cell was the highest in the column. & & & & \\
\hline
\end{tabular}

RQ2: What characteristics of healthcare professionals and their work environments impact issues with EMR systems?

\section{Years of Service}

When looking at the age and years of service for the subjects one question stood out as having significant results on the ANOVA. That question was:

"The electronic medical records system is designed more for hospital liability and less for patient care."

On this question, there were significant differences between the subjects with less experience than the ones with more experience and on younger subjects vs older subjects. The results are summarized in Table 2.

Those with less than one year of experience had significant differences with all other groups. Those with 1-5 years of experience had significant differences with subjects with 10-15 years of experience and those with 10-15 years of experience had significant differences from those subjects with $>15$ years of experience. As you can see from the 
mean scores, the more experience the subjects had the more they agreed that "The electronic medical records system is designed more for hospital liability and less for patient care."

There were significant differences between those subjects with less than 1 year and those with 10-15 years of experience. Also, there were significant differences between those subjects with 10-15 years and those with $>15$ years of experience. As you can see from Table 2, the means were higher for the 10-15 years of experience group than for the $<1$ year group and the $>15$ year group. The overall trend for all of the experience groups was higher until the $>15$ year group. The results are shown in Table 2 .

Age

The Age variable has two other questions with significant differences in the ANOVAs.

The first question that showed differences was the same as for years of service:

"The electronic medical records system is designed more for hospital liability and less for patient care."

Significant differences were observed between the 30-40 year old group (Mean 3.70) and the $>50$ year old group $($ Mean $=1.8)$ as well as between the 40-50 year old (Mean 4.00) and the 50+ group The trend in the means is lower with a large drop off with the 50+ reflected in the significant ANOVA difference.

The next question that showed differences concerned popups in the EMR interface.

"Multiple alerts/popups appear so often, that they are simply closed and never fully read (e.g. medication alerts)"

Significant differences were observed between the 20-30 year old group (Mean 2.68) and the 40-50 year old group $($ Mean $=3.00)$ as well as between the 40-50 (Mean $=4.10)$ year old and the $50+$ group (Mean $=3.00)$. The results are shown in Table 2.

Table 2. Age and years of service

\begin{tabular}{|c|c|c|c|c|}
\hline & \multicolumn{2}{|c|}{ AGE } & & \multirow{2}{*}{$\begin{array}{l}\text { Years of Service } \\
\text { Mean-Liability }\end{array}$} \\
\hline & Mean -Liability & Mean - Multiple & & \\
\hline $20-30$ & $*$ & 2.68 & $<1$ Year & 2.36 \\
\hline $30-40$ & 3.70 & 4.10 & $1-5$ years & 3.14 \\
\hline $40-50$ & 4.00 & 3.00 & $10-15$ years & 4.80 \\
\hline $50+$ & 1.80 & $*$ & $>15$ years & 2.50 \\
\hline
\end{tabular}

\section{Employment Status}

Differences were found in one question based on the subject's employment status. Differences were found with the "Scanning medications and patient barcodes is too time consuming" question between Full-time and Part-time classified subjects.

\section{DISCUSSION}

It is not surprising that for the research question, "what aspects of EMR impact patient care directly", two factors emerged as dominant ones: EMR policy compliance issues and systems designs issues. As the results suggest, latency in hospital workflow creeps in when there are multiple levels of dependencies built into the Electronic Medical Record system. For example, requiring a second healthcare provider to "verify" routine procedures or multiple alerts and popups that take a provider away from caring for the patient are ultimately detrimental to the provider's efficiency in improving patient outcomes. Systems design issues such as non-intuitive interfaces or multiple screens of repetitive data entry takes the provider away from the patient. For example, entering the patient information several times or 
getting consent release on different occasions appear to be designed to protect the hospital or organization from liability issues rather than providing the best, timely care to the patient.

Situations as mentioned above, where the healthcare provider's focus and energy is constantly challenged in meeting with paperwork requirements and following system commands, can be frustrating to the workforce on the floor providing service at the point of care to the patient. Many a times these frustrations lead to "workarounds" or ways of avoiding some of the required actions to get to the final stage, which is providing care. As mentioned by one of the nurses, it can be viewed as insulting by a nurse who has to go to another nurse and ask her to verify the right dosage of insulin that a patient needs before it is administered. It is important to ascertain the specific workflow of a particular hospital and capture that in the system that is implemented in that facility. More often than not, hospitals get a systems solution that is made from industry practices and try to mirror the systems requirements in the workflow (Patterson, 2018). More involvement of service providers at the inception and development stages of systems solution in hospitals can help these organizations to improve EMR policy compliance issues and reduce frustrations with system design issues leading to less workarounds. Table 3 provides recommendations for practitioners in this field. These recommendations are based on our data and research literature in this field.

Table 3. Research question findings with recommendations

\begin{tabular}{|l|l|l|}
\hline Research Questions & Findings & Recommendations \\
\hline $\begin{array}{l}\text { RQ1: What aspects of EMR } \\
\text { systems impact patient care } \\
\text { directly? }\end{array}$ & $\begin{array}{l}\text { EMR policy Compliance } \\
\text { issues }\end{array}$ & $\begin{array}{l}\text { Develop EMR policies that help healthcare } \\
\text { employees provide better care. } \\
\text { Refrain from adding too many dependencies } \\
\text { for the provider to complete a task. }\end{array}$ \\
\cline { 2 - 3 } & Systems design issues & $\begin{array}{l}\text { Systems need to mirror organization's } \\
\text { workflow, not otherwise. }\end{array}$ \\
\hline $\begin{array}{l}\text { RQ2: What characteristics } \\
\text { of healthcare professionals } \\
\text { and their work } \\
\text { environments impact } \\
\text { perception of issues with } \\
\text { EMR systems? }\end{array}$ & Years of service & $\begin{array}{l}\text { Communicate the importance of following } \\
\text { procedure/using system to new employees. }\end{array}$ \\
\cline { 2 - 3 } & Age of the provider & $\begin{array}{l}\text { Reach out to younger employees to train/ } \\
\text { explain benefits of using systems. }\end{array}$ \\
\hline & Employment status & $\begin{array}{l}\text { Develop performance evaluation criteria for } \\
\text { part-time employees reflective of time required } \\
\text { to fully follow process. }\end{array}$ \\
\hline
\end{tabular}

For the second research question, characteristics of healthcare professionals and how their work environment impacts usage of EMR systems, the results suggest three demographic variables have significant impact on perceptions of EMR. First, years of service of the provider has a significant relationship with the perception that the EMR is designed more for liability use than for patient care. The results show that providers with less than one year of experience had a difference in opinion with the group with more than 10-15 years of experience. This could be because they do not gain enough institutional knowledge in a short period of time to assess the real impact of EMR and its functioning. However, there was significant difference between the group with 10-15 years and the group with $>15$ years of experience in the field. These results indicate that with significant work experience if employees get into administrative positions, their perception about EMR being a "liability cover up" changes and they tend to have a more strategic view of the role of the system in service delivery.

The second demographic variable, age, showed a significant difference between groups in the ANOVA (Table 2) on the item, "electronic medical records system is designed more for hospital liability and less for patient care" and 
"Multiple alerts/popups appear so often, that they are simply closed and never fully read". The difference in perception of age groups 30-40 with the $>50$ group and 40-50 group with the 50+ group is consistent with the differences in perception with years of service. People in 50+ group tend to have administrative responsibilities and have a holistic view of the system and its role in the organization compared to younger groups of service providers.

The final demographic variable, employment status, showed differences in subjects' perception on the item, "Scanning medications and patient barcodes is too time consuming." The ANOVA result suggests a significant difference in fulltime (mean .58) and part-time classified subjects (mean 1.33).

To fully understand the implications of this, it is important to understand the difference in motivations and performance evaluation criteria for these groups in health care organizations. Typically, a full-time service provider has motivation to move up in the hierarchy and exceed performance expectations for career growth. These employees tend to follow all procedures and have long-term benefits in mind. On the other hand, part-time employees are not well invested in an organization and would have different criteria for performance evaluation. In many cases, number of patients attended or jobs performed in a day are some of the main driving factors for assessing their work.

This study has implications for theory and practice. It is a unique study exploring factors that tend to impact patient care and could potentially lead to workarounds. The factors identified in this study, EMR compliance and system design issues, can inform studies in this domain and is a significant contribution to the body of knowledge in this area. This study also has implications for practitioners such as healthcare administrators and policy makers. The recommended strategies provide prescriptive tools to "take away" and use in healthcare organizations for better patient outcomes using EMR systems. One of the limitations of this study is the use of a survey and self-reported data for its findings. Many more studies can fuel from this work leading to a better understanding of how systems can impact patient outcomes in more positive and holistic manner.

\section{CONCLUSION}

The result of this study was the answers to two research questions. First, we outlined the aspects of EMR that, if improved, will increase the quality of patient care. One such aspect is policy compliance; mainly, the fact that many operations need to be verified by another healthcare professional in order to proceed. Many nurses believe that this measure is taken exclusively to comply with the safety standards; it increases the time the patients have to wait to receive care. Another aspect is system design - unlike the compliance, which resulted mainly in one complaint, it causes multiple reported issues. The nurses report difficulties finding information and instructions, information overload from multiple tasks and popups, inability to "connect" two different EMR systems together, and many other design problems that prevent them from performing their work. The respondents gave multiple suggestions on improving the current EMR design.

Second, we determined the demographic characteristics that influence the professionals' perception of using EMR. The three significant factors that cause differences in such perception are age, level of experience, and employment status. An important step to decrease such differences is reaching out to younger and recently hired employees and communicating the importance of compliance with EMR procedures. Specific attention needs to be paid to training part-time employees to use the EMR systems quickly and effectively.

It was found that the health service providers admit numerous problems associated with their use of EMR. Many of these problems, such as having to record a high volume of information (many of which repeats itself) in a short period of time can directly impact the patient care process and the professional's interaction with the patient. Many professionals admit that they cannot spend adequate time with patients due to the amount of data they need to record. Some admit that the data entry process is very poorly organized; this causes them to spend much time looking for the necessary data entry point. Finally, we have found the issues with EMR that are related to the demographic characteristics of the professionals, such as their age and the amount of experience. As the result of the study, we provide some recommendations that will improve the professional's experience with the use of EMR and therefore improve the quality of patient care. 


\section{Issues in Information Systems}

Volume 20, Issue 2, pp. 73-82, 2019

\section{REFERENCES}

Acharya, A., Schroeder, D., Schwei, K., \& Chyou, P.H. (2017). Update on electronic dental record and clinical computing adoption among dental practices in the United States. Clinical Medicine \& Research, 15(3-4), 59-74.

Adler-Milstein, J. \& Jha, A.K. (2017). HITECH act drive large gains in hospital electronic health record adoption. Health Affairs, 36(8), 1416-1422.

Aldosari, B., Al-Mansour, S., Aldosari, H., \& Alanazi, A. (2018). Assessment of factors influencing nurses acceptance of electronic medical record in a Saudi Arabia hospital. Informatics in Medicine Unlocked, 10, $82-88$.

Aluas, M. (2016). Ethical and legal considerations of healthcare informatics. Applied Medical Informatics, 38(3-4), 91-98.

Assis-Hassid, S., Grosz, B.J., Zimlichman, E., Rozenblum, R., \& Bates, D.W. (2019). Assessing EHR use during hospital morning rounds: A multi-faceted study. PloS ONE, 14(2), 1-15.

Bae, J. \& Encinosa, W.E. (2016). National estimates of the impact of electronic health records on the workload of primary care physicians. BMC Health Services Research, 16, 172-182.

Bae, J., Rask, K.J., \& Becker, E.R. (2018). The impact of electronic medical records on hospital-acquired adverse safety events: Differential effects between single-source and multiple-source systems. American Journal of Medical Quality, 33(1), 72-80.

Barrett, A.K. (2018). Technological appropriations as workarounds: Integrating electronic health records and adaptive structuration theory research. Information Technology \& People, 31(2), 368-387.

Barrett, A.K. \& Stephens, K.K. (2017). Making electronic health records (EHRs) work: Informal talk and workarounds in healthcare organizations. Health Communication, 32(8), 1004-1013.

Choi, E.Y., Chung, E.J., \& Lee, H.S. (2006). Users' satisfaction on the electronic nursing record system. Studies in Health Technology \& Informatics, 122, 855.

DesRoches, C.M., Charles, D., Furukawa, M.F., Joshi, M.S., Kralovec, P., Mostashari, F., Jha, A.K. (2013). Adoption of electronic health records grows rapidly, but fewer than half of US hospitals had at least a basic system in 2012. Health Affairs, 32(8), 1478-1485.

Dudding, K.M., Gephart, S.M., \& Carrington, J.M. (2018). Neonatal nurses experience unintended consequences and risks to patient safety with electronic health records. Computers, Informatics, Nursing, 36(4), 167-176.

Eason, K. \& Waterson, P. (2014). Fitness for purpose when there are many different purposes: who are electronic patient records for? Health Informatics Journal, 20(3), 189-198.

Edwards, C. (2012). Nursing leaders service as a foundation for the electronic medical record. Journal of Trauma Nursing, 19(2), 111-114.

Friedman, D.J., Parrish, R.G., \& Ross, D.A. (2013). Electronic health records and US public health: Current realities and future promise. American Journal of Public Health, 103(9), 1560-1567.

Fuji, K.T., Galt, K.A., Siracuse, M.V., \& Christoffersen, J.S. (2011). Electronic health record adoption and use by Nebraska pharmacists. Perspectives in Health Information Management, 8(3), 1-9.

Gagnon, M.P., Ghandour, E.K., Talla, P.K., Simonyan, D., Godin, G., Labrecque, M., Rousseau, M. (2014). Electronic health record acceptance by physicians: Testing an integrated theoretical model. Journal of Biomedical Informatics, 48, 17-27.

Garrett, P. \& Seidman, J. (2011). EMR vs EHR - What is the difference? Retrieved from https://www.healthit.gov/buzz-blog/electronic-health-and-medical-records/emr-vs-ehr-difference 
Gesulga, J.M., Berjame, A., Moquiala, K.S., \& Galido, A. (2017). Barriers to electronic health record system implementation and information systems resources: A structured review. Procedia Computer Science, 124, 544-551.

Government Publishing Office. (2018). Code of federal regulations: Title 45 - Public Welfare: Part 162 Administrative Requirements. Washington, DC.

Halbesleben, J.R.B., Wakefield, D.S., \& Wakefield, B.J. (2008). Work-arounds in health care settings: Literature review and research agenda. Health Care Management Review, 33(1), 2-12.

Health IT Dashboard by the Office of the National Coordinator for Health IT (2018). Quick stats. Retrieved from https://dashboard.healthit.gov/quickstats/quickstats.php on 4/7/2018.

Institute of Medicine of the National Academies. (2003). Key capabilities of an electronic health record system: Letter report (ISBN 0-309-55877-8). Washington, DC: The National Academies Press.

Late electronic medical record entries create indefensible ED malpractice. ED Legal Letter, Feb 2018, 29(2), 16-17.

Meeks, D.W., Smith, M.W., Taylor, L., Sittig, D.F., Scott, J.M., \& Singh, H. (2014). An analysis of electronic health record-related patient safety concerns. Journal of the American Medical Informatics Association, 21(6), 1053-1059.

Morath, J.M. \& Turnbull, J.E. (2005). To do no harm. San Francisco, CA: Jossey-Bass.

Pagulayan, J., Eltair, S., Faber, K. (2018). Nurse documentation and the electronic health record: Use the nursing process to take advantage of EHRs' capabilities and optimize patient care. American Nurse Today, 13(9), $48-54$.

Patterson, E.S. (2018). Workarounds to intended use of health information technology: A narrative review of the human factors engineering literature. Human Factors, 60(3), 281-292.

Rathert, C., Porter, T.H., Mittler, J.N., \& Fleid-Palmer, M. (2019). Seven years after meaningful use: physicians' and nurses' experiences with electronic health records. Health Care Management Review, 44(1), 30-40.

Sackett, K., Jones, J., \& Erdley, W.S. (2005). Incorporating healthcare informatics into the strategic planning process in nursing education. Nursing Leadership Forum, 9(3), 98-104.

Sackett, K.M., Erdlet, W.S., \& Jones, J. (2006). The Western New York regional electronic health record initiative: Healthcare informatics use from the registered nurse perspective. Studies in Health Technology and Informatics, 122, 248-252.

Schiff, G.D. \& Zucker, L. (2016). Medical scribes: Salvation for primary care or workaround for poor EMR usability? Journal of General Internal Medicine, 31(9), 979-981.

Sidek, Y.H. \& Martins, J.T. (2017). Perceived critical success factors of electronic health record system implementation in a dental clinic context: An organisational management perspective. International Journal of Medical Informatics, 107, 88-100.

Stevenson, J.E., Israelsson, J., Nilsson, G., Petersson, G., \& Bath, P.A. (2016). Vital sign documentation in electronic records: The development of workarounds. Health Informatics Journal, 24(2), 206-215.

Stutzer, K. \& Rushton, C.H. (2015). Ethics in critical care: Ethical implications of workarounds in critical care. AACN Advanced Critical Care, 26(4), 372-375.

Syoubuzawa, S., Yamanouchi, K., \& Takeda, T. (2006). Nursing information processing abilities: A comparison of nursing managers and staff nurses. Studies in Health Technology and Informatics, 122, 819.

Wang, T. \& Biedermann, S. (2012). Adoption and utilization of electronic health record systems by long-term care facilities in Texas. Perspectives in Health Information Management, 1-14. 


\section{Issues in Information Systems}

Volume 20, Issue 2, pp. 73-82, 2019

Xierali, I. M., Hsiao, C.J., Puffer, J.C., Green, L.A., Rinaldo, J.C.B., Bazemore, A.W., Phillips Jr., R.L. (2013). The rise of electronic health record adoption among family physicians. Annals of Family Medicine, 11(1), 1419.

Yung, A. (2017). Adoption of electronic health record system in community-based physiotherapy clinics: A pilot case study. Studies in Health Technology \& Informatics, 234, 395-400. 